\title{
Saethre-Chotzen syndrome
}

\author{
William Reardon, Robin M Winter
}

Clinical geneticists are inured to anecdotes recounting odd presentations of dysmorphic syndromes. Saethre-Chotzen syndrome is a case in point. A consultation for schizophrenia led to the first report from the Norwegian psychiatrist, Haakon Saethre, who identified a condition characterised by craniosynostosis, low frontal hairline, facial asymmetry, brachydactyly, fifth finger clinodactyly, partial syndactyly, and vertebral column defects in his patient. ${ }^{1}$ The patient's mother and half sister also had syndactyly and cranial abnormalities. This initial report also included details of a similar, apparently sporadic case. Within a year, Chotzen ${ }^{2}$ reported a father and two sons who, in addition to craniosynostosis, had hypertelorism, facial asymmetry, palatal malformation, short stature, deafness, and mental retardation.

This unusual variability in the phenotype delayed the emergence of a well defined syndrome for 40 years until the report of Pantke et $a l,{ }^{3}$ whose systematic evaluation of six families underlined the clinical range of the condition. Moreover, these authors retrospectively identified several published cases and pedigrees which had been misdiagnosed and reported as other syndromes.

Meanwhile the confusion surrounding clinical conditions comprising craniofacial and digital anomalies had been clarified by Blank ${ }^{4}$ whose study of 34 patients with "acrocephalosyndactyly" had clearly identified Apert syndrome from non-Apert acrocephalosyndactyly. The changes in approach to classifying this group of disorders are well illustrated by comparing the approach adopted by $\mathrm{McKu}$ sick in 1966 with that of $1992 .{ }^{56}$ In the first edition of Mendelian Inheritance in Man, six separate categories of acrocephalosyndactyly were cited: type I or typical Apert syndrome, type II called Apert-Crouzon or Vogt syndrome, type III consisting solely of the reports of Saethre and Chotzen without the use of their acronym, type IV or Mohr type, type V or Waardenburg type, and type VI or Pfeiffer syndrome. Nowadays, three rather than six categories of acrocephalosyndactyly syndromes are recognised separately: types II and IV and Waardenburg have been eliminated and type III, now known after Saethre and Chotzen, has been greatly expanded. Pfeiffer syndrome continues as a distinct entry but has become type $\mathrm{V}$ and Apert syndrome remains as type I.

Although the clinical variability of Saethre-
Chotzen syndrome provides a perfect battleground for "lumpers" and "splitters", a broad consensus has now emerged as to the central features of the condition. However, such is the degree of variability and overlap with other syndromes of craniofacial growth disturbance that certain identification of the syndrome in a single case is often difficult, examination of other family members being required for confirmation in a suspected case. In addition clinically unaffected gene carriers have been noted several times ${ }^{7}$ and the response of the family to the evaluation of other apparently well persons may need to be considered. ${ }^{8}$

\section{Clinical features}

Disturbed cranial development in SaethreChotzen syndrome results in a wide variety of craniofacial abnormalities, sometimes manifesting as frank craniosynostosis. However, the mildness of the skull irregularity in some instances may lead to underdiagnosis and, consequently, the overall prevalence of craniosynostosis within the syndrome is uncertain. If present, the craniosynostosis is variable and frequently asymmetrical. Premature fusion of the coronal suture, manifesting as brachycephaly or plagiocephaly, of the metopic suture, causing trigonocephaly, and of the lambdoid suture causing occipital flattening have all been noted, in addition to frontal and parietal bossing. The disturbance of cranial development may be more subtle and late closing fontanelles, parietal foramina (fig 1), and ossification defects, as well as hyperostosis of the calvarium have all been recorded. Common clinical features resulting from abnormal cranial development, apart from craniosynostosis, are a flat forehead and a straight nasal bridge.

As noted by Saethre the frontal hairline may be low. Ptosis, hypertelorism, and facial asymmetry are well documented. The palate may be arched or, rarely, cleft and the nasal septum deviated from the midline. Lacrimal duct abnormalities are common. Typical facial features are illustrated in figs 2 and 3 . Hearing impairment, thought to reflect nerve compression, is an occasional finding. Mild external ear malformation is common, typically manifesting as small round ears which may be posteriorly rotated, while some authors have noted the prominence of the crus helicis (fig 4).

Mild syndactyly of the second interdigital space of the fingers was a feature of Saethre's description and has been reiterated by several 


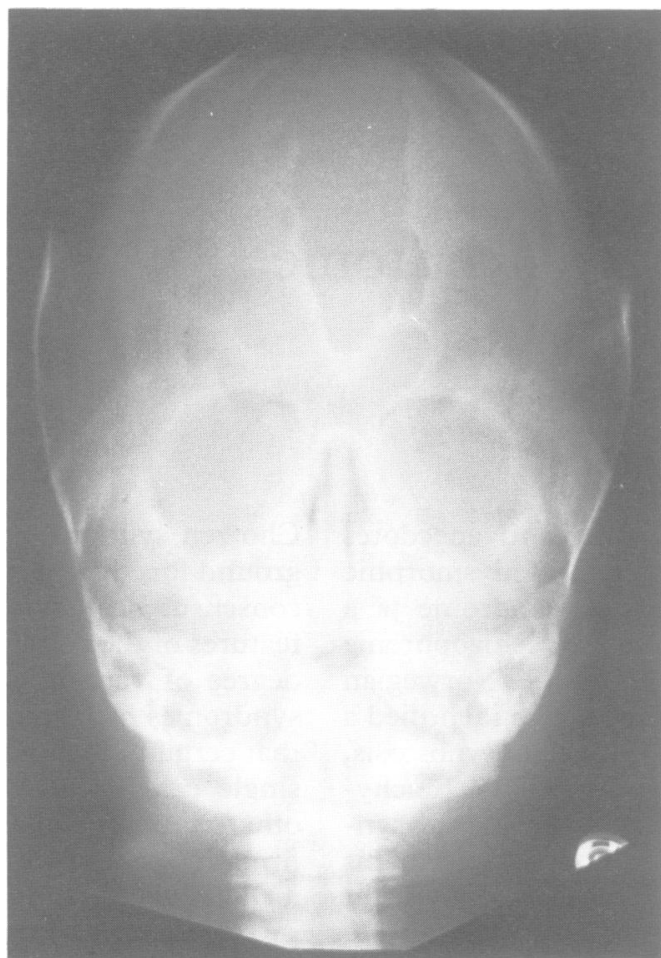

Figure 1 Skull radiograph showing fusion of the lower part of the metopic suture, the upper end of which is widely separated and continuous with large, symmetrical defects in the parietal bones, extending to the midline.

subsequent reports and by our own observations (fig 5). Syndactyly of other fingers is uncommon. The thumbs may be short and angulated or flattened (fig 6). Cutaneous syndactyly of toes 2 to 3 is well described and a broad hallux with a valgus deformity is characteristic of Saethre-Chotzen syndrome. We have observed instances of hallucal reduplication in the context of a strong family history of "classical" Saethre-Chotzen syndrome in three different families (fig 7). In addition, radiographs of clinically broad halluces may show notching of the terminal phalanges (fig 8). Other skeletal anomalies, much less frequent in prevalence, are radioulnar synostosis and vertebral fusion.
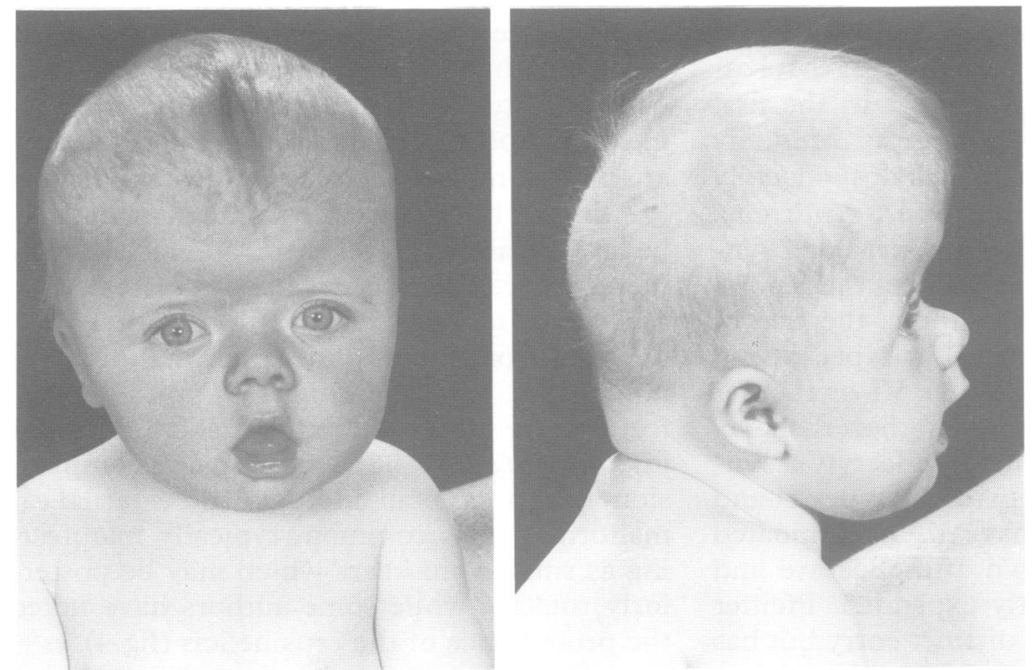

Figure 2 Typical facial features of a child with Saethre-Chotzen syndrome. Note the acrocephaly, wide prominent forehead, depressed nasal bridge, and small ears with prominence of the crus.

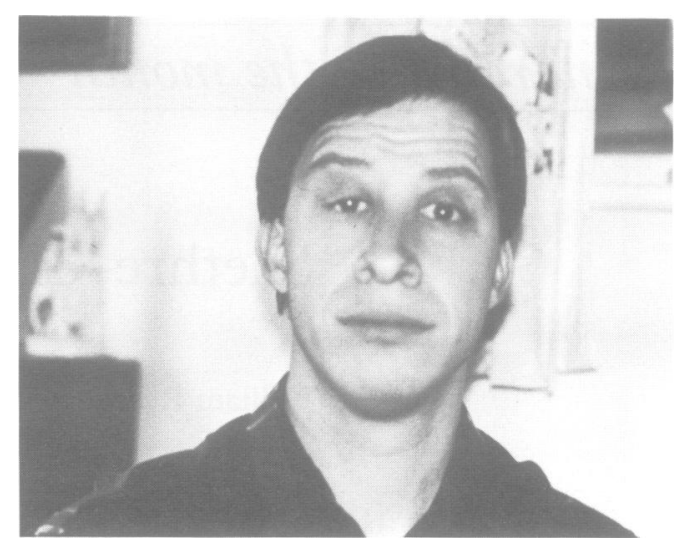

Figure 3 Adult patient with Saethre-Chotzen syndrome. Note the ptosis and frontalis overactivity.

\section{Differential diagnosis}

Some cases may be so mildly manifesting as to go undetected until evaluation of the whole family after identification of the syndrome in a child with frank craniosynostosis. In this connection it is surprising to note that Carter et $a l,{ }^{9}$ in a review of craniosynostosis, identified nine probands with Saethre-Chotzen syndrome but thought that only four were familial. Our experience suggests that most cases of Saethre-Chotzen syndrome are familial rather than sporadic, but the signs in other family members may be subtle.

Since craniosynostosis is the problem leading to presentation in many families, differential diagnosis will focus largely on craniosynostosis and its causes, whether simple or syndromic. Craniosynostosis is an aetiologically heterogeneous end stage of several complex pathophysiological processes, ${ }^{10}$ some cases of which have an underlying chromosomal abnormality. Among the autosomal dom-

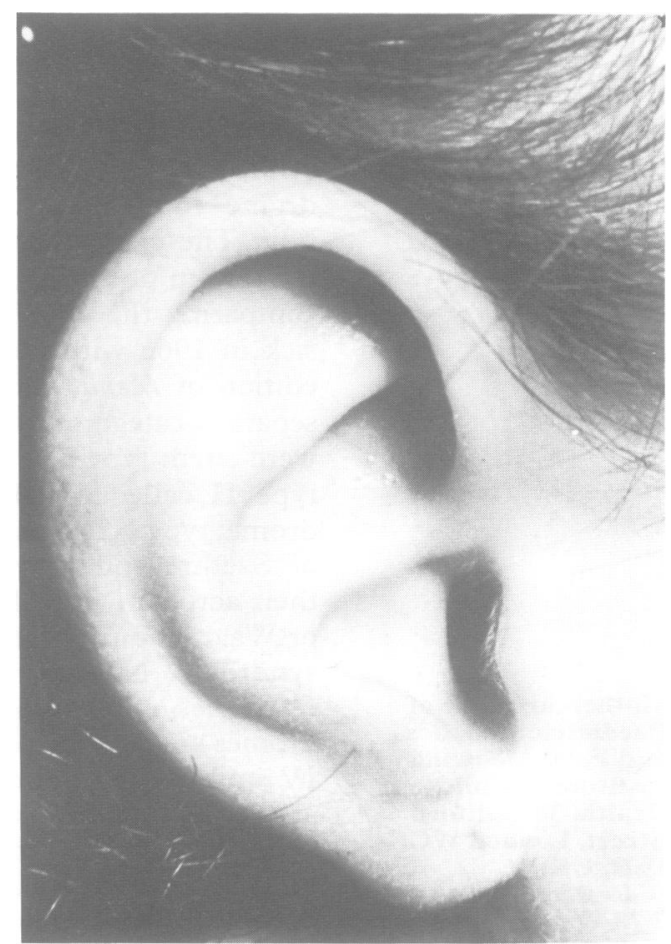

Figure 4 Prominent crus helicis in a patient with Saethre-Chotzen syndrome. 


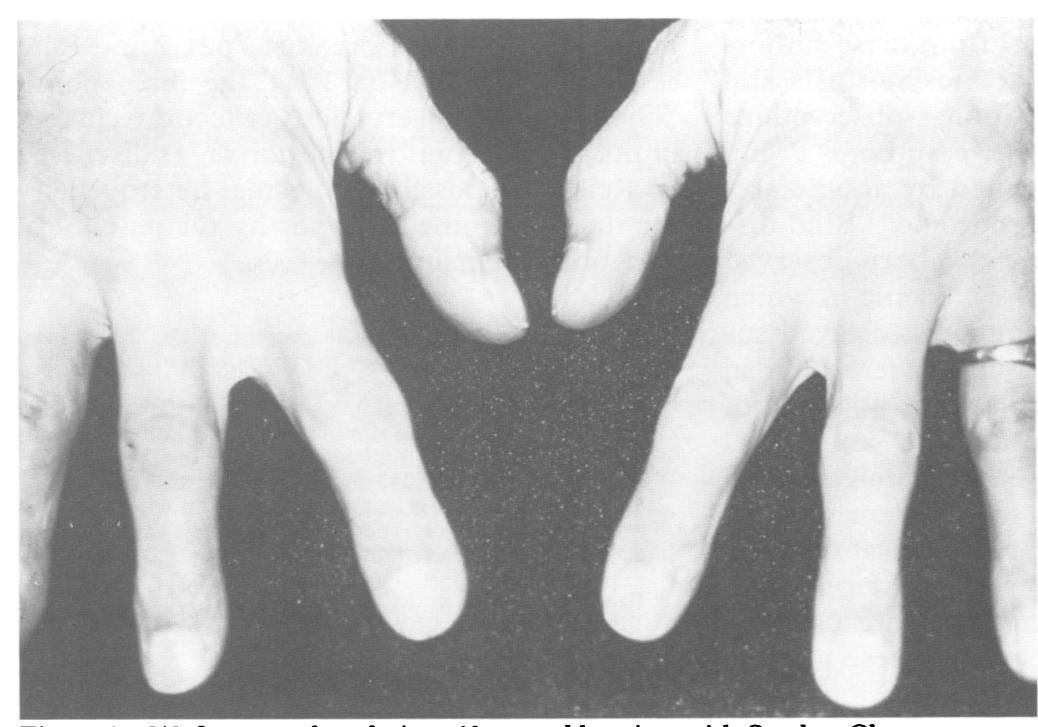

Figure 5 2/3 finger syndactyly in a 60 year old patient with Saethre-Chotzen syndrome who was otherwise clinically unidentifiable as a gene carrier.

inant forms of syndromic craniosynostosis, Saethre-Chotzen syndrome is readily identifiable from Apert syndrome by the absence of the characteristic skin and bony syndactyly of the latter condition. Crouzon syndrome is characterised by proptosis in almost all cases, a feature which is rare in Saethre-Chotzen syndrome pedigrees. Moreover the facial profile in Apert and Crouzon syndromes tends to show a more severe degree of midface hypoplasia than is usual in Saethre-Chotzen syndrome. Although patients with Pfeiffer syndrome, like Saethre-Chotzen cases, frequently have a degree of soft tissue syndactyly as well as craniosynostosis, the constant feature on which the differentiation may be based is the presence of broad thumbs and big toes, usually with a
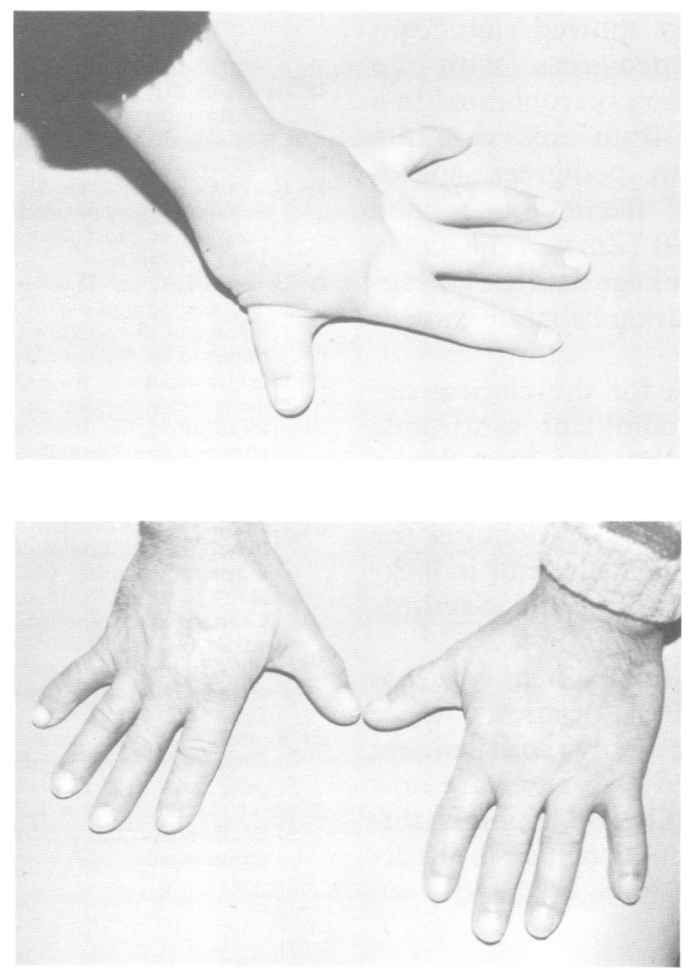

Figure 6 Short, angulated thumbs of father (below) and son (above) with Saethre-Chotzen syndrome.

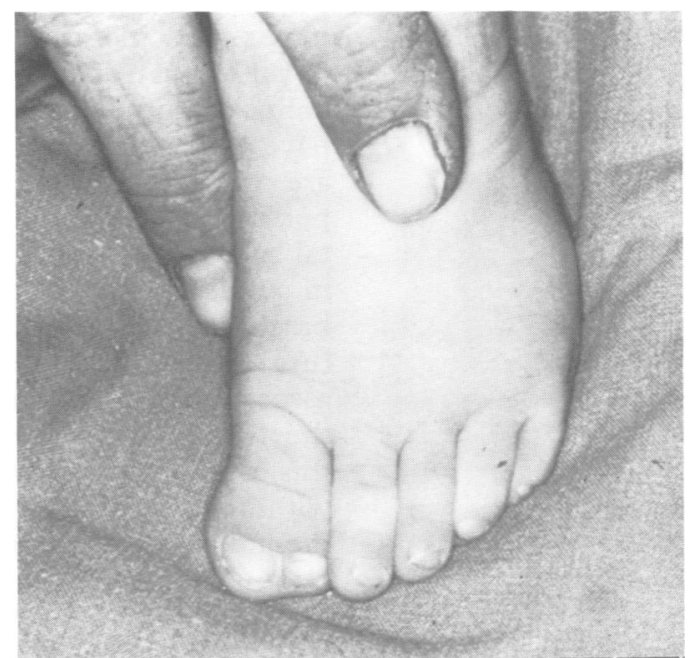

Figure 7 Hallucal reduplication observed in a single patient from a family with Saethre-Chotzen syndrome.

varus deformity in Pfeiffer cases. SaethreChotzen cases, in contrast, may have broad big toes but with a characteristic valgus deformity and the thumbs are not usually broad, although may be flattened. Jackson-Weiss syndrome represents a highly variable phenotype, the craniofacial abnormalities covering the entire spectrum of acrocephalosyndactyly syndromes, associated with medial deviation of the big toes in some cases. Clearly the differentiation between Saethre-Chotzen and Jackson-Weiss syndromes might be difficult, particularly in the single case. Indeed it has been suggested that these are allelic forms (see below).

Carter et $a l^{9}$ identified distal hallucal reduplication and a Saethre-Chotzen syndrome-like facies in two probands, and suggested a separate entity, called Robinow-Sorauf syndrome,
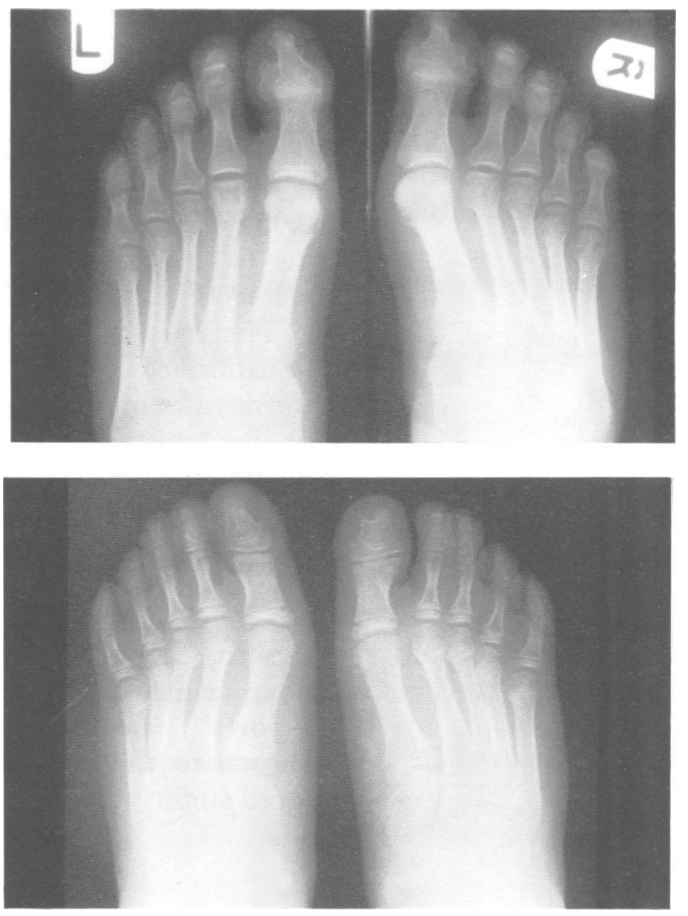

Figure 8 Degrees of terminal hallucal phalangeal notching in patients from different pedigrees. 
in recognition of the report from these authors of autosomal dominant craniosynostosis and hallucal reduplication. ${ }^{11}$ Similar observations have been recorded by other authors ${ }^{1213}$ and are probably also represented by another report labelled as Pfeiffer syndrome. ${ }^{14}$ Bifid distal hallucal phalanges have also been observed in auralcephalosyndactyly syndrome in which brachycephaly, facial asymmetry, delayed suture closure, and small pinnae were seen in association with $4 / 5$ cutaneous syndactyly of the feet. ${ }^{1516}$ While some authors ${ }^{15}$ suggested this as a separate entity, others thought it fell within the Saethre-Chotzen spectrum. ${ }^{16}$ Given the inconstant finding of radiological reduplication of the hallux in several of our own pedigrees with classical Saethre-Chotzen phenotype, it seems likely that these authors were all describing variable expression of the Saethre-Chotzen gene. ${ }^{1016}$ McKusick $^{6}$ continues to afford Robinow-Sorauf syndrome a provisional discrete entry in his catalogue. In view of these observations, it seems unlikely that there is continued justification for this.

\section{Gene localisation studies}

There is a significant association between $7 p$ deletion and craniosynostosis, 14 of 32 reported cases having this feature. ${ }^{17}$ The precise location of and extent of deletion required for craniosynostosis is the focus of some debate among cytogeneticists, ${ }^{1819}$ some favouring $7 \mathrm{p} 15$ as the likely critical area and others considering the $7 \mathrm{p} 21$ region to be more important. Based on the frequency of craniosynostosis among $7 \mathrm{p}$ deletion cases, Brueton et $a l^{20}$ performed linkage studies, using biallelic markers, on 16 pedigrees with autosomal dominant craniosynostosis segregating. Although recognising the clinical heterogeneity among their patient cohort, they showed significant linkage among their pedigrees with $7 p$ markers. This has now been corroborated in a refined patient group from six carefully selected Saethre-Chotzen pedigrees and a position of maximum likelihood refined around the locus D7S488 (Zmax 7.57, $\theta \max$ $0.05) .{ }^{21}$ Broadly similar linkage data are emerging from others investigating separate patient cohorts. $^{22}$

The true genetic basis for the clinical delineation of autosomal dominant syndromic forms of craniosynostosis has also been shown by linkage studies. Crouzon syndrome families do not map to the region of $7 p$ defining the Saethre-Chotzen syndrome locus, nor is Jackson-Weiss syndrome allelic with SaethreChotzen syndrome. ${ }^{22} 23$

Saethre-Chotzen syndrome phenotype has recently been described in association with de novo translocations of $7 p$ by two independent reports $^{245}$ and four other such cases are now known to the authors. The breakpoints differed slightly in the two published cases, Rear- don et $a l^{4}$ citing the break at $7 \mathrm{p} 21.2$ and Reid et $a^{25}$ indicating $7 \mathrm{p} 22$ as the breakpoint. Whether these observations reflect the current limits of cytogenetic resolution or, as discussed by Reid et al, possible molecular heterogeneity for this syndrome, noteworthy for its clinical variability, remains to be seen.

Figure 1 is reproduced with the consent of Drs Thompson Baraitser, and Hayward and by the permission of the Editor.

1 Saethre H. Ein Beitrag zum Turmschadelproblem (Pathogenese, Erblichkeit und Symptomologie). Dtsch Z Ner venheilkd 1931;117:533-55.

2 Chotzen F. Eine eigenartige familiare Entwicklungsstorung. (Akrocephalosyndaktylie, Dystosis craniofacial is und Hypertelorismus). Monatschr Kinderheilkd 1932;55:97-122.

3 Pantke OA, Cohen MM Jr, Witkop CJ Jr, et al. The Saethre-Chotzen syndrome. Birth Defects 1975; XI(2): 190-225.

4 Blank CE. Apert's syndrome (a type of acrocephalosyndacyly): observations on a British series of thirty nine cases. Ann Hum Genet 1960;24:151-64.

5 McKusick VA. Mendelian inheritance in man. 1st ed. Baltimore: Johns Hopkins University Press, 1966.

6 McKusick VA. Mendelian inheritance in man. 10th ed. Baltimore: Johns Hopkins University Press, 1992

7 Cohen MM Jr. Syndromes with craniosynostosis. In: Cra niosynostosis: diagnosis, evaluation and management. New niosynostosis: diagnosis, evaluation
York: Raven Press, 1986:413-590.

8 Hughes HE. Syndrome diagnosis: patient grief or physician glory? 5th Syndrome diagnosis: patient grief or physician

9 Carter CO, Till K, Fraser V, Coffey R. A family study of craniosynostosis, with probable recognition of a distinct craniosynostosis, with probable recognition
syndrome. $\mathcal{J}$ Med Genet 1982;19:280-5.

10 Cohen MM Jr. Sutural biology and correlates of craniosynostosis. Am $\mathcal{f}$ Med Genet 1993;47:581-616.

11 Robinow M, Sorauf TJ. Acrocephalosyndactyly, type Noack, in a large kindred. Birth Defects 1975;11(5):99106

12 Young I, Harper PS. An unusual form of familial acrocephalosyndactyly. $\mathcal{F}$ Med Genet 1982;19:286-8.

13 Kopysc Z, Stanska M, Ryzko J, Kulczyk B. The SaethreChotzen syndrome with partial bifid of the distal phalanges of the great toes: observations of 3 cases in one langes of the great toes: observations

14 Naveh Y, Freidman A. Pfeiffer syndrome: report of a family and review of the literature. $\mathcal{Y}$ Med Genet 1976;13:277-80. 15 Kurczynski TW, Casperson SM. Auralcephalosyndactyly: a new hereditary craniosynostosis syndrome. 7 Med Gene

16 Legius E, Fryns JP, Van Den Berghe H. Auralcephalosyndactyly: a new craniosynostosis syndrome or a variant of the Saethre-Chotzen syndrome? F Med Genet 1989;26: $522-4$.

17 Chotai KA, Brueton LA, van Herwerden L, et al. Six cases of $7 p$ deletion: clinical, cytogenetic and molecular studies. Am $\mathcal{f}$ Med Genet (submitted)

18 Aughton DJ, Cassidy SB, Whiteman DAH, Delach JA Guttmacher AE. Chromosome 7p- syndrome: craniosy nostosis with preservation of region $7 \mathrm{p} 2$. Am $\mathcal{F}$ Med Genet 1991;40:440-3.

19 Kikkawa K, Narahara K, Tsuji K, Kubo T, Yokoyama Y, Seino Y. Is loss of band $7 \mathrm{p} 21$ really critical for manifestation of craniosynostosis in $7 \mathrm{p}-$ ? Am $\mathcal{f}$ Med Genet 1993;45:108-10.

20 Brueton LA, van Herwerden L, Chotai KA, Winter RM The mapping of a gene for craniosynostosis: evidence fo linkage of the Saethre-Chotzen syndrome to distal chromosome 7p. 7 Med Genet 1992;29:681-5.

21 van Herwerden L, Rose CP, Reardon W, et al. Evidence for locus heterogeneity in acrocephalosyndactyly: a refined ocalisation for the Saethre-syndrome locus on distal chromosome 7p and exclusion of Jackson-Weiss syn-

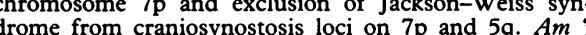
Hum Genet (in press)

22 Lewanda AF, Cohen MM Jr, Jackson CE, et al. Genetic heterogeneity among craniosynostosis syndromes: mapping the Saethre-Chotzen syndrome locus between Crouzon syndrome loci from $7 \mathrm{p}$. Genomics (in press).

23 Reardon W, van Herwerden L, Rose C, Jones B, Malcolm $\mathrm{S}$, Winter RM. Crouzon syndrome is not linked to $\mathrm{S}$, Winter RM. Crouzon syndrome is not linked to 1994;31:219-21.

24 Reardon W, McManus SP, Summers D, Winter RM. Cytogenetic evidence that the Saethre-Chotzen syndrome Cytogenetic evidence that the Saethre-Chotzen syndrome 25 Reid CS, McMorrow LE, McDonald-McGinn DM et al. Saethre-Chotzen syndrome with familial translocation at chromosome 7p22. Am $\mathcal{F}$ Med Genet 1993;47:637-9. 